\title{
A tale of two valleys: endangered species policy and the fate of the giant gartersnake
}

\author{
BRIAN J. HALSTEAD ${ }^{1 *}$, PATRICIA VALCARCEL ${ }^{2}$, RICHARD KIM ${ }^{1}$, \\ ANNA C. JORDAN ${ }^{1}$, JONATHAN P. ROSE ${ }^{3}$, SHANNON M. SKALOS ${ }^{1}$, \\ GABRIEL A. REYES ${ }^{1}$, JULIA S. M. ERSAN ${ }^{1}$, MICHAEL L. CASA- \\ ZZA $^{1}$, ALLISON M. ESSERT $^{1}$, AND ALEXANDRIA M. FULTON ${ }^{1}$
}

${ }^{1}$ U.S. Geological Survey, Western Ecological Research Center, Dixon Field Station, 800 Business Park Drive, Suite D, Dixon, CA 95620, USA

${ }^{2}$ WRA, Inc., 2169-G Francisco Boulevard East, San Rafael, CA 94901, USA

${ }^{3}$ U.S. Geological Survey, Western Ecological Research Center, Santa Cruz Field Station, Santa Cruz, CA 95060, USA

*Corresponding Author: bhalstead@usgs.gov

By the mid-20th Century, giant gartersnakes (Thamnophis gigas) had lost more than $90 \%$ of their Central Valley marsh habitat and were extirpated from more than two-thirds of their range. This massive habitat loss led to their inclusion in the inaugural list of rare species under the California Endangered Species Act (CESA). Listing under the CESA provided giant gartersnakes legal protection and mechanisms for recovery, and subsequent listing under the U.S. Endangered Species Act (federal ESA) further fortified these protections. But how effective has listing under these endangered species acts (ESAs) been at achieving their goal of giant gartersnake recovery? Herein, we review relevant aspects of giant gartersnake ecology, illustrate how listing has benefited giant gartersnakes and what challenges have been faced in slowing declines and recovering populations, and chart a course toward improved conservation, management, and recovery of giant gartersnakes. Although listing as threatened under both state and federal ESAs has not yet achieved recovery of giant gartersnakes, the increased knowledge gained and mechanisms for protecting giant gartersnake habitat on private and public lands developed over the past 50 years has improved conservation of this endemic California snake.

Key words: Central Valley, conservation, garter snake, private land, rice, Thamnophis gigas, water management, wetlands

Giant gartersnakes (Thamnophis gigas) are semi-aquatic snakes endemic to marshes, sloughs and other stagnant or slow-moving aquatic habitats of California's Central Valley. Although they once ranged through all but the most northern portions of the Central Valley, 
the loss of wetlands has extirpated them from about two-thirds of their historical range. Because of this loss of habitat, giant gartersnakes were among the inaugural list of rare species under the California Endangered Species Act (CESA; California Department of Fish and Game Commission 1971). Herein, we review giant gartersnake biology and the conditions leading to their listing as rare, discuss how listing has helped conserve giant gartersnakes and what challenges have been encountered, and chart a path toward giant gartersnake recovery.

\section{GIANT GARTERSNAKE BIOLOGY AND LISTING HISTORY}

\section{Description}

Giant gartersnakes currently range from Butte County to Fresno County, although few populations remain in the southern portion of their range (Fig. 1; Hansen and Brode 1980; Ernst and Ernst 2003; Wylie and Amarello 2006). Body coloration in giant gartersnakes is typically brown or olive with a yellow dorsal stripe and a light-yellow lateral stripe on either side of the body (Fig. 2). Between the dorsal and lateral stipes are paired rows of dark blotches. The ventral surface is generally pale olive yellow in color, though giant gartersnakes exhibit variation in color from overall darker specimens with dark olive dorsal and lateral stripes to snakes with vivid orange dorsal and lateral stripes and peach-colored ventral surfaces. Historically, giant gartersnakes reached a maximum total body length of $162.6 \mathrm{~cm}$, making them the largest species of gartersnake (Ernst and Ernst 2003). From 1995 to 2020, the largest giant gartersnake captured and measured by the U.S. Geological Survey (USGS) was $142.0 \mathrm{~cm}$ total length in 2019 (U.S. Geological Survey, unpublished data). Large giant gartersnakes are thick-bodied snakes, reaching weights of up to $930 \mathrm{~g}$. Female giant gartersnakes reach larger sizes than males (Wylie et al. 2010), though males reach their maximum size quicker with a faster growth rate (Rose et al. 2018b).

\section{Population and Community Ecology}

Because of their secretive nature, estimating abundance of giant gartersnake populations and understanding giant gartersnake population ecology requires intensive field study and sophisticated analytical methods. Long-term capture-mark-recapture (CMR) studies of giant gartersnakes have provided valuable information on demographic vital rates and their contribution to population growth. Giant gartersnake annual survival rates increase with higher emergent vegetation cover at a site and higher precipitation the previous year (Rose et al. 2018c), and with individual size. Hansen et al. (2015) found a linear increase in annual survival with snout-vent length (SVL), whereas Rose et al. (2018c) found that survival increased with SVL up to a peak for individuals near $800 \mathrm{~mm} \mathrm{SVL}$, followed by a plateau or slight decrease for even larger individuals. Female fecundity also increases with size (Rose et al. 2018a), and the greater reproductive value of large adult females means that the survival of this life stage has the greatest influence on population growth rates (Rose et al. 2019). The growth and survival rates of juvenile (1 year old) giant gartersnakes also have an important influence on population growth, especially when the probability of recruitment from neonate to 1 year old is higher (Rose et al. 2019). The value of large females and growth and survival of juvenile snakes suggests the importance of prey availability to the life history of giant gartersnakes.

Historically, giant gartersnakes likely preyed on soft-rayed fishes and amphibians, likely including some locally extinct species (Rossman et al. 1996). Around the turn of the 


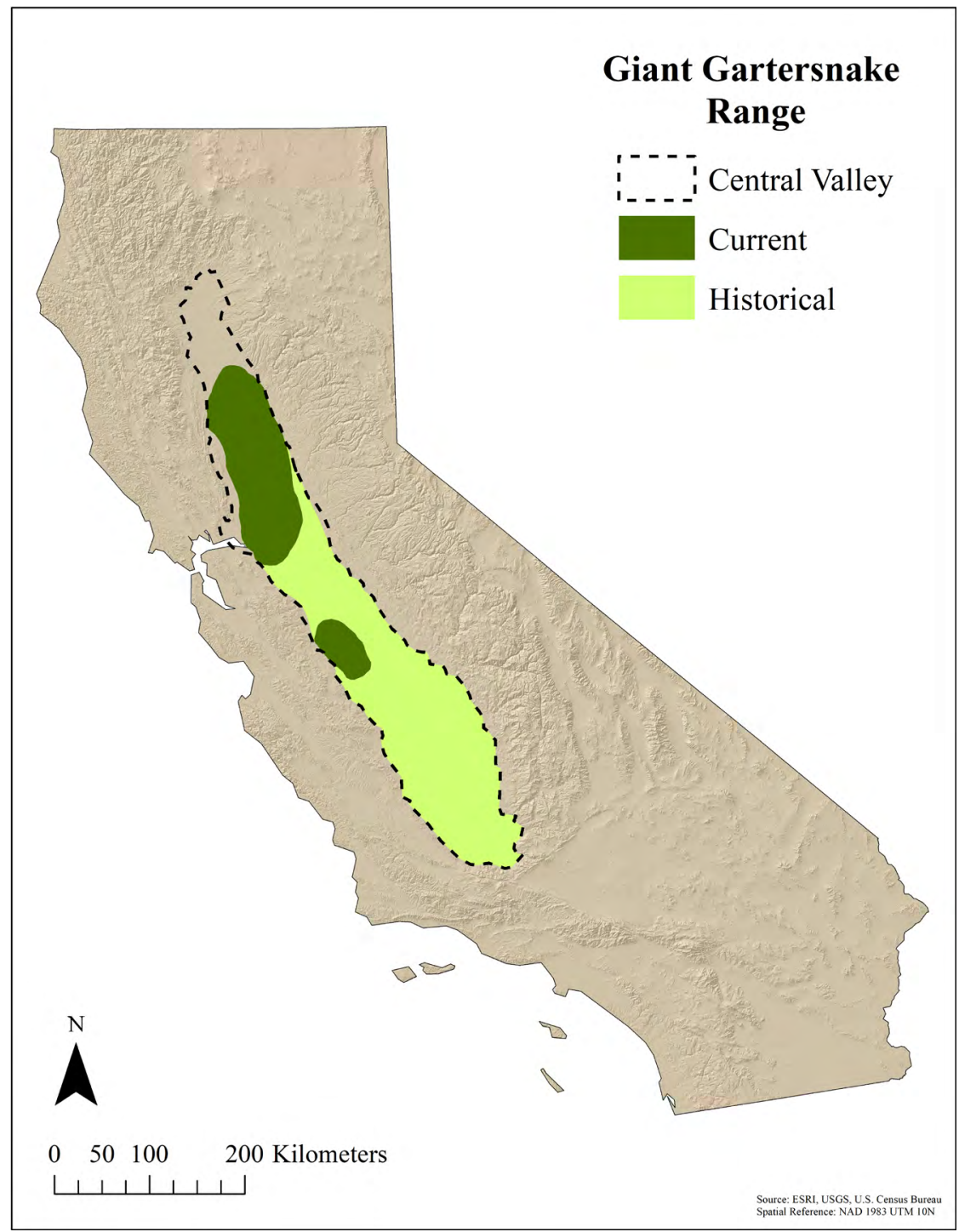

Figure 1. Estimated giant gartersnake (Thamnophis gigas) historical and current ranges based on Rossman et al. (1996), California Department of Fish and Wildlife (2016), and California Natural Diversity Database (CNDDB; 2020).

century, many generalist fish species and American bullfrogs (Lithobates catesbeianus; hereinafter bullfrogs) were introduced from the eastern United States and have dramatically changed the prey composition available to giant gartersnakes. Despite the dominance of nonnative prey, giant gartersnakes retain a preference for native anurans and generally select anurans (native and introduced) over introduced fishes (Ersan et al. 2020a, 2020b). Naïve neonate giant gartersnakes in the laboratory respond most strongly to extracts of and most readily consume larval and adult Sierran treefrogs (Pseudacris sierra; Ersan et al. 


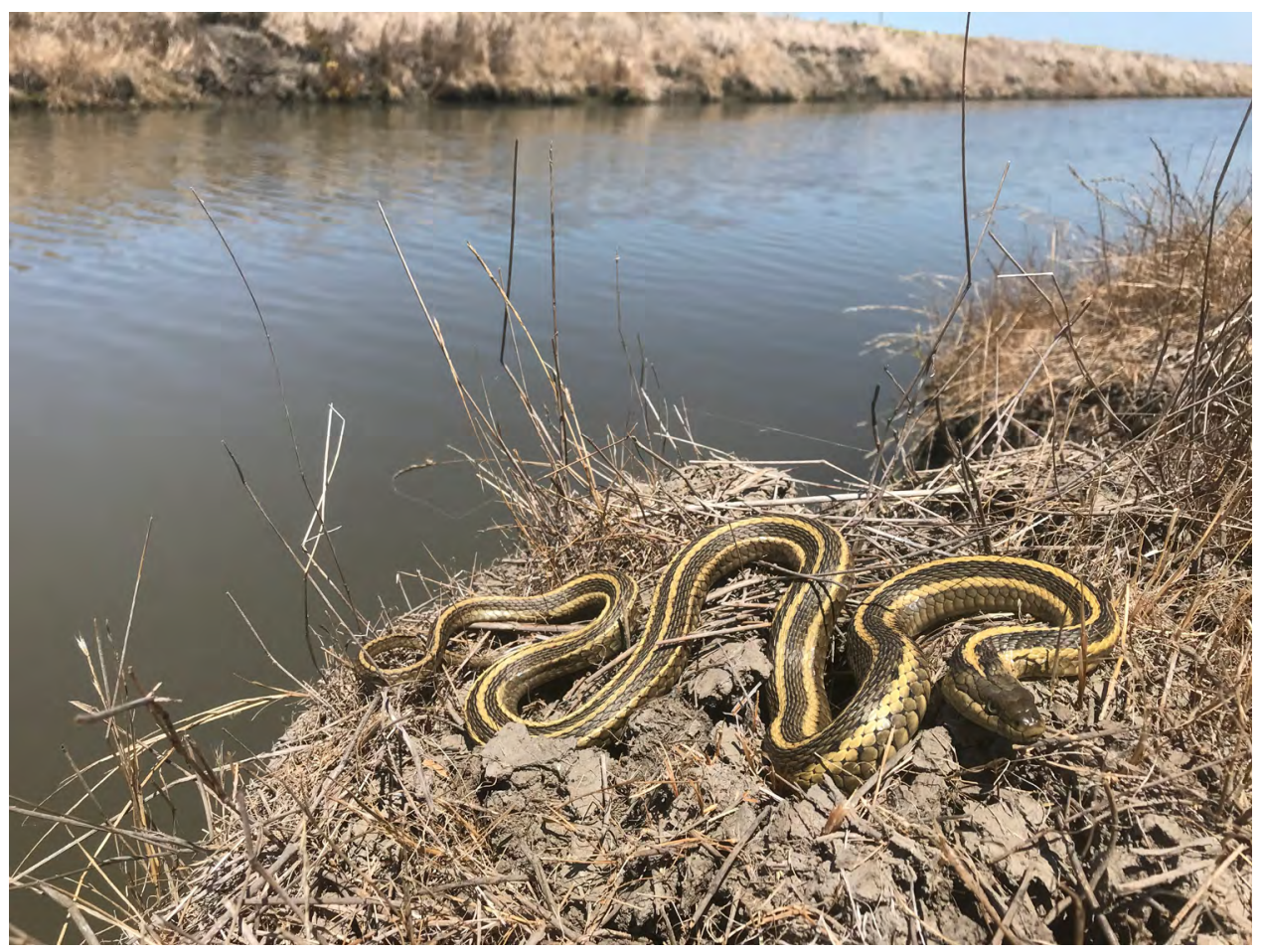

Figure 2. An adult giant gartersnake (Thamnophis gigas) next to a canal in habitat typical of the rice agricultural landscape in which most extant populations occur. U.S. Geological Survey photograph taken by Elliot Schoenig.

2020a), and wild giant gartersnakes also strongly select native treefrogs (Ersan et al. 2020b). Although bullfrog tadpoles and juveniles also are positively selected as prey (Ersan et al. 2020a, 2020b), adult bullfrogs are predators of small giant gartersnakes (Wylie et al. 2003).

Giant gartersnakes are prey to a variety of native and nonnative vertebrates. Mesopredators, especially North American river otters (Lontra canadensis); wading birds; and raptors eat giant gartersnakes, and smaller predators like American mink (Neovison vison) likely take small giant gartersnakes. Introduced predators, particularly large centrarchid fishes, also prey on giant gartersnakes. Although giant gartersnakes can eat the young of these introduced fishes, they are less important as prey than bullfrogs, and because they deplete native frog populations (Adams et al. 2003), their presence is unlikely to benefit giant gartersnakes in any meaningful way. The effects of bullfrogs, however, are less clear, because they serve both as important prey and predators. Ongoing research seeks to elucidate the intraguild predation relationship between giant gartersnakes and bullfrogs to develop bullfrog management strategies that result in the greatest benefit to giant gartersnakes. Regardless of the predator, however, the influence of predation at the population level might be somewhat ameliorated by habitat structure.

\section{Habitat, Past and Present}

The Central Valley historically comprised a network of rivers and floodplains supporting expansive permanent and seasonally flooded freshwater marshes and shallow lakes 
across several drainage basins (Frayer et al. 1989; Garone 2011). Marshes were primarily characterized by emergent vegetation, predominantly hardstem bulrushes (Schoenoplectus acutus; colloquially and hereinafter referred to as "tules") and cattails (Typha spp.). In the contemporary landscape, giant gartersnakes spend $>50 \%$ of their time in the active season on land basking or using cover such as rodent burrows, with most of this terrestrial time spent within $10 \mathrm{~m}$ of water (Halstead et al. 2015). During brumation, nearly all snakes are found underground in the terrestrial environment (Halstead et al. 2015).

Today, the Central Valley has lost $>90 \%$ of its historical marshes due to agricultural conversion and urban development (Frayer et al. 1989; Garone 2011). Floodplains have been permanently altered by levees built to protect development and agriculture, and artificial water delivery canals have replaced the network of rivers and sloughs that once supported natural marshes and lakes (Frayer et al. 1989; Garone 2011). Most extant giant gartersnake populations are associated with rice agriculture in the Sacramento Valley, where the network of canals, drains, and rice fields themselves provide marsh-like habitat during the giant gartersnake active season (Halstead et al. 2010). Although rice agriculture supports giant gartersnake populations, simplification of habitat structure and mismatches in the phenology of rice agriculture and giant gartersnake ecology limit its suitability relative to marshes (Halstead et al. 2010, 2012, 2019; Wylie et al. 2010). Nonetheless, giant gartersnakes with less rice in and near their home ranges have lower survival; therefore, giant gartersnakes are considered reliant on rice agriculture in the Sacramento Valley (Halstead et al. 2019).

\section{Conservation Status}

The California Endangered Species Act (CESA) was enacted in 1970 to conserve and protect native plant and animal species at risk of extinction in the state of California. When the CESA was first enacted, it included take restrictions on killing, trapping, collecting, and harming individuals; however, harm is no longer included in the definition of take (Dwyer and Murphy 1995). The giant gartersnake was declared rare in 1971, as one of the 42 animals inaugurally protected under state law. The primary reason for initial listing was habitat loss caused by land development and conversion from wetlands to agriculture in the Sacramento and San Joaquin valleys (Hansen and Brode 1980). This classification was later changed to threatened in the 1984 amendment of the CESA. The take, possession, purchase, or sale of threatened species is prohibited under state law (California Fish and Game Code, section 2080 et seq.). The California Department of Fish and Wildlife (CDFW) may authorize take incidental to lawful activity if the effects of the take are minimized and fully mitigated and taking would not jeopardize the species' continued existence (California Fish and Game Code, section 2080 et seq.). Habitat mitigation is often a requirement to fully mitigate take of CESA species.

Giant gartersnakes were listed as threatened under the U.S. Endangered Species Act (federal ESA) in 1993 (USFWS 1993), and the finalized recovery plan was completed in 2017 (USFWS 2017). Giant gartersnakes benefit from further protection under the federal ESA because the federal regulatory definition of "harm" (50 CFR $§ 17.3)$ more clearly includes significant modification or degradation of habitat of imperiled species where such activity kills or injures wildlife by impairing essential breeding or feeding behavioral patterns (Dwyer and Murphy 1995). Although the federal ESA provides for the designation of critical habitat for threatened and endangered species, no critical habitat has been designated for giant gartersnakes. This dual listing under both the federal ESA and the CESA allows for 
more complete protection of giant gartersnakes and their habitat throughout their current range such as when new projects like dams and diversions arise.

The federal Recovery Plan for the Giant Gartersnake highlights six key recovery criteria (USFWS 2017). The first and second stipulate that sufficient habitat is classified under protected status such that populations are supported, and that these populations are connected with corridors of suitable habitat. The third criterion states management plans and best management practices oriented to giant gartersnake conservation are developed and implemented using adaptive management. The fourth and fifth require protected habitat to be supplied with a reliable source of clean water during the active months of the giant gartersnake, and that threats like disease are reduced or removed. The sixth and final recovery criterion requires that monitoring of recovery units demonstrates stable or increasing populations over a 20-year period, including at least one 3-year drought (USFWS 2017). Although these recovery criteria are related to the species' status under the federal ESA, by meeting these criteria the conditions of habitat loss and urbanization under which giant gartersnakes were first listed under the CESA will no longer pose an extinction risk. These criteria provide a roadmap for the recovery of the giant gartersnake, and the eventual delisting under both the U.S. and California ESAs.

Giant gartersnakes have been protected under the CESA for more than 50 years, and under the federal ESA for more than 25 years, and it is appropriate to ask how listing as threatened under both ESAs has promoted the persistence of giant gartersnakes, and what challenges remain unaddressed by listing. In the remainder of this paper, we examine these questions and suggest a path forward to further benefit giant gartersnake conservation.

\section{INFLUENCE OF LISTING ON GIANT GARTERSNAKE CONSERVATION}

\section{How has listing helped giant gartersnakes?}

The listing of giant gartersnakes under the California and federal ESAs has benefited giant gartersnake conservation in several ways, including (1) providing a mechanism to offset habitat loss by restoring and preserving marshes and funding research to guide recovery; (2) encouraging the development of programs to protect private landowners conducting habitat improvement in good faith or maintaining appropriate conditions for listed species on their lands; (3) changing construction practices to account for giant gartersnakes; (4) influencing water management, particularly water transfers across large distances within California; and (5) increasing knowledge about and concern for the species.

Conservation and restoration of marsh habitat in the Central Valley has accelerated over the past several decades. The increased focus on wetland restoration and management has benefited giant gartersnakes in two ways: (1) increased conservation and restoration of marshes through incentive programs and mitigation requirements and (2) improved wetland management for the benefit of giant gartersnakes. Private landowners, non-governmental organizations, and state and federal refuges have conserved or constructed nearly 90,000 ha of marsh habitat in the Central Valley as of 2015 (Central Valley Joint Venture 2020). Although giant gartersnake conservation has not been the impetus for much of this wetland restoration, these efforts aid in the giant gartersnake's persistence across the contemporary fragmented landscape. Publicly conserved lands within the current range of the giant gartersnake include eight national wildlife refuges, 23 state wildlife or ecological areas, and preserves under partnership management such as Cosumnes River Preserve. These lands 
are often publicly accessible and have multiple land management goals that balance public use and wildlife habitat management. Many of these public lands have focused habitat management to include objectives for giant gartersnakes and some, such as Colusa National Wildlife Refuge and the Cosumnes River Preserve (among others), have enhanced and restored habitats that benefit giant gartersnakes. Lands managed by public entities can provide opportunities for partnerships to restore or enhance lands with multi-benefit objectives. The California Department of Water Resources has engaged with multiple partners to restore habitat for both winter waterfowl and giant gartersnakes on lands that may be managed for subsidence reversal or for other purposes. These multi-benefit projects include the western Sacramento-San Joaquin Delta, including Sherman and Twitchell islands where giant gartersnakes have been documented following restoration (CNDDB 2020).

Compensatory mitigation that can contribute to species conservation is driven by public and private actions as a result of requirements from California and federal ESA permits for effects to giant gartersnakes or their habitat. Projects that require permits can be small scale ditch or culvert repair, wetland restoration, or large-scale projects such as the state or federal water projects for water transfers. The type of conservation land is categorized by the permit and mitigation route and generally falls into three categories: conservation banks, permittee-responsible mitigation, and reserve systems in Habitat Conservation Plans (HCPs) or Natural Community Conservation Plans (NCCPs). These lands typically are not publicly accessible and management goals are focused on species and their habitats. To become approved as banks or other mitigation, restoration and enhancement approved by the U.S. Fish and Wildlife Service (USFWS), CDFW, or both must also include long-term management and not just preservation of habitats (Bunn et al. 2013). Although typically not accessible to the general public, these lands offer research opportunities similar to public conservation lands, and conservation banks such as Gilsizer Slough Giant Garter Snake Conservation Complex and Natomas Basin Conservancy reserves have provided long-term access to research and monitoring (e.g., Halstead et al. 2012, 2015, 2016; Rose et al. 2018c, 2018b, 2019).

The overall footprint of remaining giant gartersnake habitat is certainly enhanced through a variety of means under the influence of both California and federal ESAs. The mitigation lands in the Natomas Basin associated with the HCP alone account for 1600 ha of giant gartersnake habitat that otherwise would not be created or protected. The presence of giant gartersnakes at Colusa National Wildlife Refuge (NWR) was a primary consideration in the purchase of additional inholdings (formerly rice fields) that are now managed for summer water for giant gartersnakes within Tract 24. A major source of the acquisition funding for this purchase came from compensatory mitigation for the Central Valley Project (CVP) through the Central Valley Project Improvement Act (CVPIA) Habitat Restoration Program (HRP). These are just a few examples of habitat being created or conserved because of the giant gartersnake's threatened status under the CESA and the federal ESA.

Safe Harbor Agreements (SHAs) are another mechanism used by USFWS and CDFW to enable conservation and restoration actions on private land, which provides the most habitat for giant gartersnakes. When implemented, SHAs allow for continued commercial, agricultural, or industrial use of habitats as long as baseline habitat conditions are maintained, and habitat restoration, minimization of negative effects, or mitigation are implemented in good faith. Safe Harbor Agreements usually allow for incidental take of listed species during certain activities, including implementing beneficial activities, conducting routine ranching and farming activities, and returning properties to baseline habitat conditions. Two safe 
harbor agreements have been implemented for giant gartersnakes under USFWS: A 2013 SHA with the Sacramento River Conservation Area Forum and a 2007 Yolo County SHA with Audubon California. Combined, these SHAs cover 81,000 ha within the range of giant gartersnakes, and the agreements have a duration of 30 years. Although SHAs were codified into state law in 2009 , both SHAs covering giant gartersnakes have been implemented solely under federal law.

Another group of programs developed to encourage conservation on private lands is Habitat Exchange Programs (HEPs). Habitat exchange programs allow private landowners to sell mitigation credits for listed species habitat on their lands with the agreement to maintain or improve habitat. Habitat quality and quantity are assessed by an independent entity with oversight from CDFW and USFWS, and better-quality habitat sells at a higher price per acre than poorer quality habitat. Thus, habitat preservation and improvement are incentivized by market forces. Two farms in the Sacramento Valley are currently selling credits for giant gartersnakes under the Central Valley HEP, with a total of nearly 1,600 ha enrolled as of 2020. Habitat Exchange Programs and SHAs are not mutually exclusive; indeed, habitat enhancements to benefit a landowner enrolled in an HEP are often covered by an SHA.

In addition to habitat protection and restoration, the listing of giant gartersnakes has changed some construction practices for the benefit of giant gartersnakes. Seasonal restrictions on groundwork between October and May for permitted projects near wetlands and canals within the range of giant gartersnakes prevents disturbance to overwintering snakes, when most snakes are underground and vulnerable to disturbance (Halstead et al. 2015). This and similar avoidance and minimization measures to limit negative effects to giant gartersnakes would not be in place without listing under the CESA and the federal ESA.

Listing has further resulted in a focus on the effects of water management practices on the species. Recognition of the detrimental effects of wetland loss on wetland-dependent wildlife and the role of the CVP in conversion of wetlands to other uses resulted in the passage of the CVPIA in 1992. The CVPIA mandates changes in CVP management, primarily to benefit fish and wildlife and their habitats through habitat protection, restoration, and management and research to support these efforts. In addition to the CVPIA, the transfer of water through state or federal facilities requires review under the federal ESA, the CESA, or both. Water transfers are perhaps the largest scale and most frequent action that affects giant gartersnakes and requires environmental review. Indeed, water transfers have stimulated and funded the most substantive research on giant gartersnakes both to understand the effects of and mitigate for water transfers from the Sacramento Valley to other parts of California.

One of the greatest benefits listing has conferred to giant gartersnakes is promoting an understanding of the species. Indeed, much of what was known about giant gartersnakes prior to listing was based on historical accounts from sites long since drained for agriculture (e.g., Van Denburgh and Slevin 1918; Fitch 1940; Wright and Wright 1957). From listing under the CESA in 1971 until listing under the federal ESA in 1993, interest in giant gartersnakes from the scientific and conservation communities increased, and an important thesis on the ecology of giant gartersnakes by Hansen (1980) and several important reports documenting the status of giant gartersnakes (e.g., Hansen and Brode 1980; Hansen 1986, 1987) were published. Additional research continued in the late 1990s and early 2000s, but it was not until the provision of larger amounts of longer-term funding for research, largely driven by water transfers, that peer-reviewed research on giant gartersnake ecology and conservation rapidly increased (Fig. 3). 


\section{What challenges remain for giant gartersnake protection and recovery, despite listing?}

Despite the numerous ways listing has benefited giant gartersnakes, many challenges to giant gartersnake conservation remain. The limited definition of take under the CESA, which does not include "harm," means that indirect effects to giant gartersnake habitat by projects without federal involvement are often not consulted on or mitigated for. The lack of coverage under the CESA for loss of habitat and focus directly on killing, trapping, and collecting is especially problematic for secretive and cryptic species like giant gartersnakes. For these species, direct effects are rarely observed, and more insidious habitat conversion, particularly on agricultural lands, is problematic.

Both the CESA and the federal ESA have allowances for normal agricultural practices to continue in the presence of listed species except in the instance of take or when there is a major land conversion (agriculture to other uses, such as commercial or residential development). Crop rotation or permanent conversion, pest control, infrastructure maintenance, or other routine agricultural activities often do not trigger either ESA. Such activities, including conversion of rice to row crops or orchards, pesticide applications, and dredging of canals or grading of canal banks, can, however, negatively affect giant gartersnake populations. When a species like the giant gartersnake largely occurs in an agricultural landscape, most populations are unprotected and reliant on the continuation of conditions that allow them to persist or voluntary conservation actions by private landowners. Although programs like SHAs and HEPs exist to encourage conservation on private lands, these have been underutilized for giant gartersnake conservation.

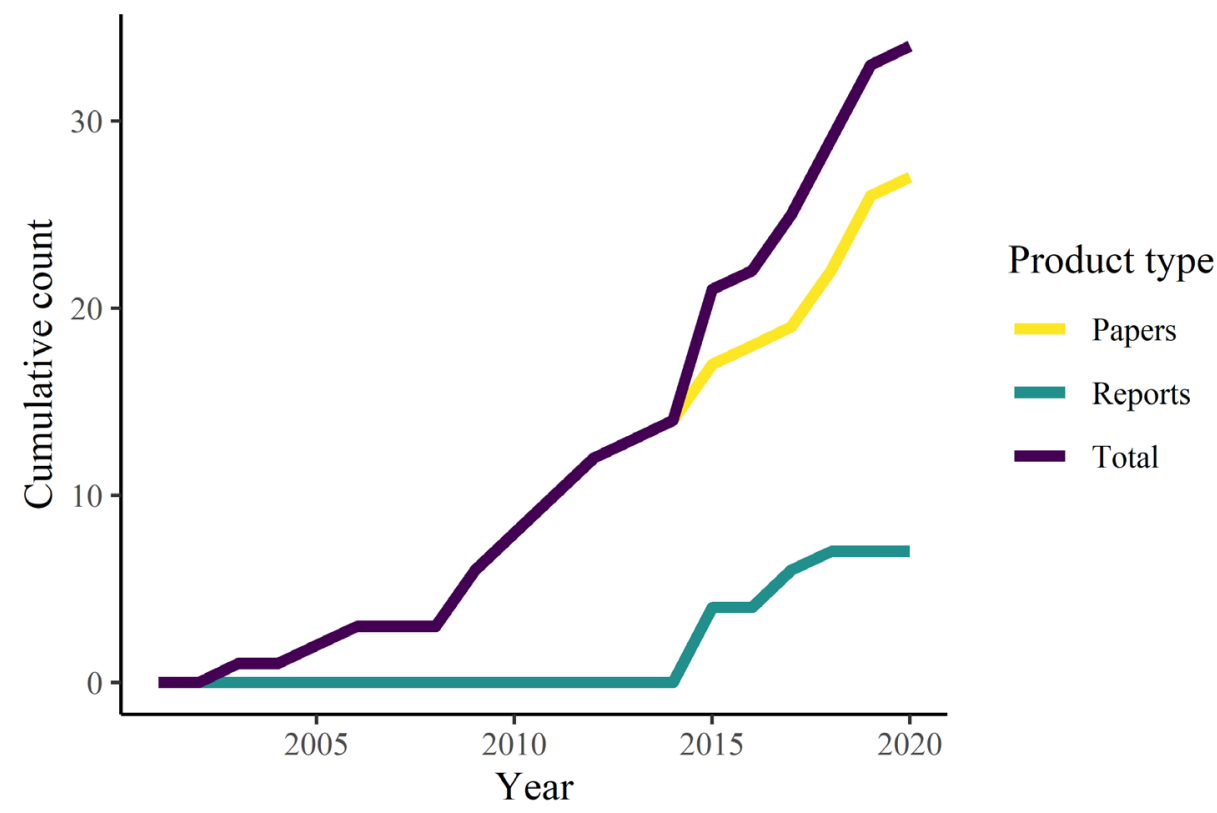

Figure 3. Cumulative number of peer-reviewed journal articles and publicly-available peer-reviewed reports (U.S. Geological Survey Open-File Reports) from a Web of Science ${ }^{\mathrm{TM}}$ search from 1985-2020 using the search terms Topic $=$ "giant garter*" OR Topic = "Thamnophis gigas." Six peer-reviewed papers in the results were removed because they were not about giant gartersnakes, but compared results for other species to giant gartersnakes. 
Agricultural practices do trigger environmental review including ESA processes when state or federal facilities for water transfers are used. In the case of rice agriculture, this primarily occurs when water is sold from water rights holders in the Sacramento Valley to other parts of California and must pass through state or federal water project facilities to reach buyers. Although water transfers have received recent attention because of their potential effects on wetland-dependent wildlife, much remains to be learned about their short-term and cumulative effects on giant gartersnakes and the adequacy of conservation measures for protecting populations.

The attention given to water transfers notwithstanding, the procurement of active season water for giant gartersnakes warrants additional attention. Habitat Conservation Plans and NCCPs often have provisions for emergency water supplies, for example by augmenting surface water with well water. This makes HCPs and NCCPs a valuable resource for giant gartersnake conservation because a reliable supply of water to support marshes from April through October is essential for giant gartersnakes (Halstead et al. 2019). The importance of appropriate water management for giant gartersnakes can be illustrated by comparing the Sacramento Valley, where most extant giant gartersnake populations occur, and the San Joaquin Valley, where few populations remain.

\section{A Tale of Two Valleys}

The decision to list giant gartersnakes under the CESA in 1971 was primarily because giant gartersnakes were nearly extirpated from the San Joaquin Valley (Hansen and Brode 1980) with conversion of marsh habitat to cotton and other unsuitable row crop agriculture and orchards (Musoke and Olmstead 1982; Frayer et al. 1989; Garone 2011). The Tulare Basin in particular suffered extensive habitat loss with the 197,000 ha Tulare Lake completely drained by the early 1900s and most of its extensive tule marsh habitat, which represented $>33 \%$ of the giant gartersnake's range, now largely eliminated (Fitch 1940; Hansen and Brode 1980; Garone 2011). Only a few isolated snake populations remain in the San Joaquin Valley and Sacramento-San Joaquin Delta today (Hansen and Brode 1980; Hansen 1987; Sloan 2004; Dickert 2005), and surveys south of Fresno in 2006 failed to detect giant gartersnakes despite marsh habitat restoration in some locations (Wylie and Amarello 2006).

In contrast to the conversion of wetlands to orchards and row crops in the San Joaquin Valley, in the Sacramento Valley a mosaic of remnant historical tule marshes (Halstead et al. 2014, 2016), constructed marshes for waterfowl hunting (Frayer et al. 1989; Reyes et al. 2017), and widespread rice agriculture and associated water delivery and drainage canals (Hansen and Brode 1980; Halstead et al. 2010; Reyes et al. 2017) continue to support populations of giant gartersnakes. Rice agriculture acts as surrogate marsh habitat and, in addition to tule marshes, is also used for waterfowl hunting, which may further protect rice from conversion to other types of agriculture unsuitable for giant gartersnakes. Changes in rice irrigation practices (Torbick and Salas 2014; Linquist et al. 2015), water availability in adjacent canals (Anderson et al. 2017), and ongoing drought leading to rice idling, as well as a rise in conversion to nut tree agriculture (Sleeter et al. 2017) continue to threaten giant gartersnakes in the Sacramento Valley. Despite these remaining challenges, giant gartersnake populations in the Sacramento Valley have unquestionably fared better than those farther south. 
The contrast between the two valleys begs the following questions:

1.If rice weren't grown in the Sacramento Valley, would listing have prevented declines like those observed in the San Joaquin Valley?

2. Will its status as a state and federally threatened species recover giant gartersnake populations, or at least maintain existing populations into the future?

The answer to question (1), we suspect, is no. This answer is, in part, because land conversion from wetlands to agriculture had occurred prior to implementation of the CESA. If the land that was converted to rice agriculture had been converted to another crop, the result in the Sacramento Valley likely would have been the same as in the San Joaquin Valley. Giant gartersnakes might have fared slightly better in the Sacramento Valley because of a few remnant wetlands and generally greater water availability than in the San Joaquin Valley, but large-scale extirpation likely would have occurred.

We examine the answer to question (2) below, where we explore ways that the threatened status of the giant gartersnake can be leveraged to improve conservation efforts for the species and the research that will further inform recovery and management of giant gartersnakes.

\section{A PATH FORWARD}

Giant gartersnake conservation and recovery in the future can be fostered in several ways. The first is more widespread implementation of appropriate water management for giant gartersnakes. For the most part, water management to support giant gartersnake populations is well-known: they require surface water that persists throughout the active season and is available perennially. Critical habitat for giant gartersnakes, while formally undefined, is inextricably linked to water supply, distribution, and application across the Central Valley landscape. Limitations to water on the landscape related to water supply, cropping patterns, or wetland restoration can have large effects on giant gartersnake populations. The challenge in managing water for giant gartersnakes is like that for other water management issues in California, including increasing variability in precipitation patterns (Swain et al. 2018) and generally increasing demand for water for a variety of uses. Future water supply may further be affected by changes to how groundwater is managed in California given California's Sustainable Groundwater Management Act, which was passed by the legislature in 2014 , and the potential uncertainty associated with local control of groundwater resources (Kiparsky et al. 2017).

Recent conservation efforts in the Sacramento Valley have focused on a floodplain restoration approach, which attempts to integrate the needs of fish, birds, and other wildlife (https://www.biographic.com/raised-in-rice-fields/). Understanding how wetland-dependent species like giant gartersnakes fit into multi-species conservation programs will be a challenge as different target species require water in different locations and seasons. Given the reliance of giant gartersnakes on inundated wetlands during the April-October active season, when water is present on the landscape is critical (Halstead et al. 2019). The potential to retain winter water for waterfowl later in the spring (i.e., through March and April) through water management in post-harvest rice fields could prove to be very beneficial to giant gartersnakes, which often emerge from brumation sites with little to no nearby flooded habitats (Halstead et al. 2019). Efforts to promote March and April water availability for migrating shorebirds also might benefit giant gartersnakes. The potential to have a greater number of post-harvest rice fields or associated ditches with water and food present offers 
an opportunity for increased body condition, survival, and potentially reproductive success for giant gartersnakes. With proper planning and input, a multi-species strategy that better incorporates the life history needs of the snake could be developed.

Most state and federal refuges in the Sacramento and San Joaquin valleys are managed in large part for wintering waterfowl. This type of management involves seasonally flooding wetlands in the late summer and fall and then draining in the late winter to encourage growth of vegetation that provides food for waterfowl. This food production period results in a large extent of seasonally dry wetland areas primarily during the giant gartersnake active season. Although most of the refuges maintain some level of spring and summer flooded wetlands, it is usually less than $15 \%$ of managed habitats and often, depending on water availability, much less than that (Central Valley Joint Venture 2020). The lack of summer wetlands available in the Central Valley may be affecting the success of breeding waterfowl in California, which make up an important component of the state's waterfowl harvest (De Sobrino et al. 2017; Central Valley Joint Venture 2020). Thus, working within the state and federal refuge systems and helping secure water on the landscape during the spring and summer may provide a win-win for waterfowl and giant gartersnakes on public lands. Achieving giant gartersnake conservation and recovery goals will largely depend, however, on the cooperation of private landowners.

Encouraging private landowners to more fully utilize existing conservation incentives would almost certainly benefit giant gartersnakes. The vast majority of giant gartersnake populations occur on private lands, and it is unlikely that sufficient wetland acreage under public ownership could be acquired to support persistent giant gartersnake populations. Moreover, relying solely on public lands for giant gartersnake conservation ignores opportunities for reconciliation ecology (Rosenzweig 2003) and win-win solutions whereby rice farmers can continue their livelihood and perhaps enhance their lands for giant gartersnakes and other wetland-dependent wildlife. Programs like SHAs and HEPs exist, but only two examples of each program have been implemented in the Sacramento Valley, with at least one farm participating in the Central Valley HEP also enrolled in an SHA. Encouraging enrollment in these and other conservation programs will benefit giant gartersnakes in their Sacramento Valley stronghold.

Relatively small modifications to rice cultural practices could have large effects on giant gartersnake populations. For example, grading or removing vegetation from canal banks, particularly in winter when nearly all giant gartersnakes are brumating underground (Halstead et al. 2015), could kill large numbers of giant gartersnakes. Conducting these activities during the active season or on short stretches of a single side of a canal could minimize negative effects of canal management. Maintaining large, contiguous areas of rice agriculture to the extent possible would increase survival of adult giant gartersnakes and benefit giant gartersnake populations (Halstead et al. 2019; Rose et al. 2019). Finally, maintaining a mosaic of open water and emergent vegetation, especially tules, in canals can provide cover and foraging opportunities for giant gartersnakes. Encouraging these actions through SHAs and HEPs could benefit rice farmers and provide important habitat enhancements for giant gartersnake populations.

Habitat Conservation Plans and NCCPs also could play a more prominent role in giant gartersnake conservation. Large portions of the historical range of giant gartersnakes do not have HCPs that include giant gartersnakes, including key counties with extant snake populations (e.g., Colusa, Glenn, and most of Sutter counties in the Sacramento Valley and 
Merced County in the San Joaquin Valley; Greco 2020). Moreover, many HCPs that are not also approved as an NCCP include only a jeopardy standard (i.e., stable populations or no net loss), rather than the recovery standard (i.e., positive population growth) adopted by NCCPs (Greco 2020). Habitat Conservation Plans and NCCPs often have a landscape scale approach, and in areas without HCPs, mitigation can be piecemeal without regard for larger conservation goals or spatial context (Greco 2020). The development of HCPs, however, is to offset incidental take, so in practice it is unclear how they would be implemented in areas without development pressure. Nonetheless, a regional approach to conservation that includes wider adoption of HCPs and NCCPs with recovery standards would likely benefit giant gartersnakes by promoting recovery (rather than loss prevention) and emphasizing connectivity among populations.

The modification of the landscape giant gartersnakes inhabit challenges our concept of what constitutes a giant gartersnake population. Although five genetic clusters largely corresponding with drainage basins are well-defined, it is unclear how populations are structured within drainage basins (Wood et al. 2015). Demographic studies of giant gartersnakes thus far have focused on treating populations as discrete units (e.g., Hansen et al. 2015; Rose et al. 2018c). Given the network of irrigation canals that make up a majority of giant gartersnake habitat, connectivity among populations is likely important for determining viability at the landscape scale (Greco 2020). For example, it is unknown whether certain high-quality habitats (e.g., wide, permanently inundated canals; restored wetlands) act as sources that support viable, growing giant gartersnake populations while others (e.g., narrow, seasonally inundated canals) are sinks or only transiently occupied. Studies that integrate capture-markrecapture or occupancy data from many sites and explicitly model the effect of distance between populations (e.g., network distance in canal habitat) on survival, population growth, colonization, and extinction rates could inform future management and conservation actions. Spatial capture-recapture models can explicitly relate individual capture data to movement and habitat connectivity (Royle et al. 2018) and have the potential to reveal how landscape structure affects giant gartersnake population dynamics. If metapopulation dynamics are important for sustaining giant gartersnake populations in fragmented habitat, plans designed to manage aquatic and terrestrial habitats at the landscape scale will be necessary to ensure viability in the long term. Identifying the appropriate spatial scale(s) for management will be increasingly important as urbanization encroaches upon and fragments remaining habitat and increases road density and traffic creating vehicle strike risks (Brehme et al. 2018; USFWS 2020). Rice fallowing and reduction in the network of water-filled canals caused by drought and water transfers further reduce connectivity among populations, and in the nearterm might have stronger effects than urbanization on most giant gartersnake populations.

The challenges and unknowns faced with maintaining extant giant gartersnake populations increase when conservation actions meant to improve and recover giant gartersnakes are considered. For example, optimizing the design and management of giant gartersnake habitat restoration projects remains an important unknown in giant gartersnake recovery. Although much has been learned in the past decade about giant gartersnake habitat selection (Valcarcel 2011; Halstead et al. 2016; Reyes et al. 2017), formal evaluation of giant gartersnake colonization and use of restored wetlands is incomplete. Optimum ratios of aquatic active season and terrestrial brumation habitat remain unknown, as does habitat selection of male, neonate, and juvenile snakes that are too small for current radio telemetry methods. A related question is whether giant gartersnake use of terrestrial environments is an artifact of 
the contemporary landscape, where expansive marshes with dense, persistent tule patches are rare. The lower survival of giant gartersnakes in linear habitats, like canals, challenges restoration design to maximize water and emergent vegetation edge without creating potential population sinks where giant gartersnakes might be more susceptible to predators like otters (Halstead et al. 2012). Water management issues, such as whether groundwater is an acceptable substitute for surface water and what bathymetry best supports all life stages of giant gartersnakes while minimizing the suitability of marshes for introduced predatory fishes, also need quantitative evaluation. Finally, balancing timing and methods of canal and marsh management, such as pesticide use, drying for vegetation control and removal of aquatic invasive species, and dredging and grading to maintain water flow, among other practices, with giant gartersnake ecology remains largely anecdotal and awaits further detailed study.

Because giant gartersnake populations inhabit a region with well-established populations of invasive aquatic plants and animals, understanding the interactions of giant gartersnakes with invasive species and the effects of invasive species management on giant gartersnakes is essential. For example, invasive plants, like water hyacinth (Eichornia spp.) and water-primrose (Ludwigia spp.), prevent efficient water flow and left unchecked can completely cover canals. Although the open water-vegetation interface selected by giant gartersnakes (Valcarcel 2011) can be maintained with chemical and mechanical control, the effects of these practices on giant gartersnakes are not well understood (Halstead et al. 2016). In addition to habitat alteration by plants, two species of watersnakes from the eastern U.S. (southern watersnakes, Nerodia fasciata, and common watersnakes, $N$. sipedon) have been introduced to the Sacramento area and could compete with giant gartersnakes if their introduced ranges expand (Rose and Todd 2014). Other introduced aquatic animals like bullfrogs and fishes can be both prey for and predators of giant gartersnakes (Wylie et al. 2003), complicating the effects of invasive species management. The mix of positive and negative effects of invasive species on giant gartersnakes requires careful planning of both invasive species control regimes and habitat management for giant gartersnakes. For example, it is possible that improving wetland habitat or water management regimes for giant gartersnakes can simultaneously benefit aquatic invasive species, thereby slowing the recovery of giant gartersnakes. Therefore, reducing habitat suitability for invasive species, providing structural refuge for giant gartersnakes, or some degree of culling invasive predators and competitors in restored marshes might improve giant gartersnake demographic rates and the likelihood of a successful establishment at restored or enhanced sites. At sites where Sierran treefrogs persist, minimizing the effects of invasive species on these native frogs can facilitate the recovery of the snakes' preferred native prey. Synergistically pairing invasive predator removal with translocation has improved recovery of imperiled species such as the endangered Sandy Cay rock iguana (Cyclura rileyi cristata) and the endangered humpback chub (Gila cypha; Spurgeon et al. 2015; Hayes et al. 2016).

Understanding the tradeoffs resulting from invasive species as prey, predators, and competitors can be the key to understanding when and how invasive species control might bolster the outcome of ongoing conservation actions for giant gartersnakes. A stronger net negative effect of an invasive species on giant gartersnakes likely points to a higher utility of controlling the invasive species below a management threshold (Noonburg and Byers 2005). For example, the estimated annual loss of snake recruitment caused by bullfrogs (Wylie et al. 2003) might be overcompensated by the snakes frequently preying on pre-metamorphic and juvenile bullfrogs. Because giant gartersnakes prefer bullfrogs over invasive fish prey (Ersan 
et al. 2020a, 2020b), it is possible that where Sierran treefrogs are rare or extirpated, bullfrogs may be an important prey source to sustain the snake population (Rose et al. 2018b, 2019).

Future studies on giant gartersnakes can aim to assess the tradeoffs between invasive species' benefit as prey and harm as competitors and predators, as demonstrated in theoretical studies (Schellekens and van Kooten 2012) and experimental studies on the endangered Mohave tui chub (Siphateles bicolor mohavensis) and invasive mosquitofish (Gambusia spp.; Henkanaththegedara and Stockwell 2014). These tradeoffs could be examined using mathematical models to compare, for example, projected population growth rate of the snakes under alternative invasive species control scenarios, including a "no control" scenario. Results from these studies could inform the degree to which controlling invasive species might facilitate the recovery of giant gartersnakes when paired with other ongoing conservation efforts.

Full recovery of giant gartersnakes will not be achieved without re-establishing populations where snakes have been extirpated using translocation (USFWS 2017). Translocation, or the human-assisted movement of individuals from one location to another, can be a useful tool for species conservation and can be of two different types: conservation translocations and mitigation translocations (Germano and Bishop 2009). Historically, translocations in snakes have been dominated by mitigation translocations to reduce human-animal conflicts, either to remove nuisance individuals or to remove animals from sites undergoing development as an impact minimization measure (Germano et al. 2015). Mitigation translocations often have unknown or variable success rates. Despite being well funded, mitigation translocations often fail to select translocation sites that meet the ecological requirements of the animals being moved and do not adequately monitor animals following translocation (Germano et al. 2015). This can result in animals returning to the area from which they were removed or failing to thrive in the less suitable location. Mitigation translocations are further complicated when the species biology directly opposes the construction objectives or timeline. For example, construction activities in irrigation canals and rice agriculture infrastructure are most feasible during the winter when water in canals is drawn down and fields are fallowed, but this timeframe coincides with the giant gartersnake inactive season when snakes are overwintering in burrows along the banks of canals and are most vulnerable to disturbance (Hansen 2013; Halstead et al. 2015). Even if special care is taken to translocate snakes out of the construction area, snakes that are moved during the inactive season will likely be more vulnerable to mortality than if they were disturbed during the active season. Such mitigation translocations are generally used to minimize mortality in extant snake populations, whereas conservation translocations have the explicit goal of species recovery.

Conservation translocations, which are planned to introduce populations to or augment them in suitable protected habitat, have the potential to be more successful than mitigation translocations because the objectives align with the biological needs of the species and are designed with species preservation and recovery in mind. Conservation translocation has not yet been attempted in giant gartersnakes, but the U.S. Geological Survey is currently implementing a small-scale translocation within the American Basin genetic cluster. The southern region of the American Basin has been heavily developed, and despite recent efforts to restore habitat in the region, the southern sub-population has failed to recover (ICF International 2018). Adults and captive-reared juveniles from the more abundant central sub-population are being translocated into the restored wetland complex in the southern basin with the goals of bolstering the southern sub-population and identifying best practices for 
future translocations. If translocated giant gartersnakes survive, reproduce, and establish a growing population, the strategy could be used to re-establish populations in the San Joaquin and Tulare basins to address one of the nine recovery actions for the species (USFWS 2017), provided that threats are ameliorated and a reliable supply of water is available. Translocating adult giant gartersnakes might be most efficient because adult female survival has the greatest influence on giant gartersnake population growth rates (Rose et al. 2019), but removing these snakes could negatively affect donor populations. On the other hand, because giant gartersnake population growth rate also is sensitive to juvenile survival and somatic growth rates (Rose et al. 2019), captive rearing of giant gartersnakes could reduce effects to donor populations while augmenting small populations or establishing new populations. Successful translocation also opens the possibility to introduce new alleles to populations with high inbreeding or low genetic diversity (Wood et al. 2015) and assist in the colonization of restored wetland habitat in the future.

\section{CONCLUSION}

Giant gartersnake conservation has undoubtedly benefited by listing under both the California and U.S. endangered species acts. Both acts brought attention to the extent of habitat loss experienced by the species and stimulated investment in research and habitat restoration. Although many unknowns remain, much has been learned about giant gartersnakes in the 50 years since listing under the CESA, and research has accelerated substantially in the past decade. Key elements of giant gartersnake recovery will be managing water to ensure it is available to giant gartersnake populations during the spring and summer, encouraging conservation on private lands, managing invasive species, addressing the challenges of climate change and changing land use, and restoring giant gartersnakes to portions of their range from which they have been extirpated. Thus, fully recovering giant gartersnakes will require substantial investment in habitat restoration, ensuring a reliable water supply, and research into conservation translocations and other management practices. Despite these challenges, we expect that the science and practice of giant gartersnake conservation will continue to improve in the next 50 years.

\section{ACKNOWLEDGMENTS}

We thank Glenn Wylie for his role in establishing U.S. Geological Survey research on giant gartersnakes, and the scores of technicians that have contributed their time and talents to our research over the past 26 years. Rachel Zwillinger provided a valuable review of the manuscript. This work was made possible with funding from the U.S. Geological Survey, Western Ecological Research Center. Any use of trade, product, or firm names is for descriptive purposes only and does not imply endorsement by the U.S. Government.

\section{LITERATURE CITED}

Adams, M. J., C. A. Pearl, and R. B. Bury. 2003. Indirect facilitation of an anuran invasion by non-native fishes. Ecology Letters 6:343-351.

Anderson, K., E. Houk, S. Mehl, and D. L. Brown. 2017. The modeled effects of rice field idling on groundwater storage in California's Sacramento Valley. Journal of Water Resource and Protection 9:786-798.

Brehme, C. S., S. A. Hathaway, and R. N. Fisher. 2018. An objective road risk assessment 
method for multiple species: ranking 166 reptiles and amphibians in California. Landscape Ecology 33:911-935.

Bunn, D., M. Lubell, and C. K. Johnson. 2013. Reforms could boost conservation banking by landowners. California Agriculture 67:86-95.

California Department of Fish and Game Commission (FGC). 1971. Animals of California declared to be endangered or threatened. Sacramento, CA, USA.

California Department of Fish and Wildlife (CDFW). 2016. Giant Gartersnake Range. Available from: http://data-cdfw.opendata.arcgis.com/datasets/fa34760c66d941cba652ac244255c518_0 (September 2020).

California Natural Diversity Database (CNDDB). 2020. RareFind5. Sacramento, CA, USA.

Central Valley Joint Venture. 2020. Central Valley Joint Venture Implementation PlanConserving Bird Habitat. Sacramento, CA, USA.

Van Denburgh, J., and J. R. Slevin. 1918. The garter-snakes of western North America. Proceedings of the California Academy of Sciences 8:181-270.

Dickert, C. 2005. Giant garter snake surveys at some areas of historic occupation in the Grasslands Ecological Area, Merced Co. and Mendota Wildlife Area, Fresno Co., California. California Fish and Game 91:255-269.

Dwyer, L. E., and D. D. Murphy. 1995. Fulfilling the promise: reconsidering and reforming the California Endangered Species Act. Natural Resources Journal 35:735-770.

Ernst, C. H., and E. M. Ernst. 2003. Snakes of the United States and Canada. Smithsonian Books, Washington, D.C., USA.

Ersan, J. S. M., B. J. Halstead, E. L. Wildy, M. L. Casazza, and G. D. Wylie. 2020a. Intrinsic prey preference of the giant gartersnake: a threatened predator in an nonnative prey-dominated community. Journal of Fish and Wildlife Management 11:164-173.

Ersan, J. S. M., B. J. Halstead, E. L. Wildy, M. L. Casazza, and G. D. Wylie. 2020b. Giant gartersnakes (Thamnophis gigas) exploit abundant nonnative prey while maintaining their appetite for native anurans. Herpetologica 76:290-296.

Fitch, H. S. 1940. A biogeographical study of the ordinoides artenkreis of garter snakes (genus Thamnophis). University of California Publications in Zoology 44:1-150.

Frayer, W. E., D. D. Peters, and H. R. Pywell. 1989. Wetlands of the California Central Valley: status and trends 1939-mid-1980's. U.S. Fish and Wildlife Service, Region 1 , Portland, OR, USA.

Garone, P. 2011. The Fall and Rise of the Wetlands of California's Great Central Valley. University of California Press, Berkeley, CA, USA.

Germano, J. M., and P. J. Bishop. 2009. Suitability of amphibians and reptiles for translocation. Conservation Biology 23:7-15.

Germano, J. M., K. J. Field, R. A. Griffiths, S. Clulow, J. Foster, G. Harding, and R. R. Swaisgood. 2015. Mitigation-driven translocations: Are we moving wildlife in the right direction? Frontiers in Ecology and the Environment 13:100-105.

Greco, S. E. 2020. Assessing range-wide "contribution to recovery" by multiple local governments for a threatened species. Ecology and Society 25:13.

Halstead, B. J., J. P. Rose, G. A. Reyes, G. D. Wylie, and M. L. Casazza. 2019. Conservation reliance of a threatened snake on rice agriculture. Global Ecology and Conservation 19:e00681. 
Halstead, B. J., S. M. Skalos, G. D. Wylie, and M. L. Casazza. 2015. Terrestrial ecology of semi-aquatic giant gartersnakes (Thamnophis gigas). Herpetological Conservation and Biology 10:633-644.

Halstead, B. J., P. Valcarcel, G. D. Wylie, P. S. Coates, M. L. Casazza, and D. K. Rosenberg. 2016. Active season microhabitat and vegetation selection by giant gartersnakes associated with a restored marsh in California. Journal of Fish and Wildlife Management 7:397-407.

Halstead, B. J., G. D. Wylie, and M. L. Casazza. 2010. Habitat suitability and conservation of the giant gartersnake (Thamnophis gigas) in the Sacramento Valley of California. Copeia 2010:591-599.

Halstead, B. J., G. D. Wylie, and M. L. Casazza. 2014. Ghost of habitat past: historic habitat affects the contemporary distribution of giant garter snakes in a modified landscape. Animal Conservation 17:144-153.

Halstead, B. J., G. D. Wylie, P. S. Coates, P. Valcarcel, and M. L. Casazza. 2012. Bayesian shared frailty models for regional inference about wildlife survival. Animal Conservation 15:117-124.

Hansen, E. C. 2013. Biggs-West Gridley Water District Gray Lodge Wildlife Area Water Supply Project giant garter snake (Thamnophis gigas) habitat and impact assessment. Sacramento, CA, USA.

Hansen, E. C., R. D. Scherer, G. C. White, B. G. Dickson, and E. Fleishman. 2015. Estimates of survival probability from two populations of giant gartersnakes in California's Great Central Valley. Copeia 103:1026-1036.

Hansen, G. E. 1986. Status of the giant garter snake Thamnophis couchi gigas (Fitch) in the southern Sacramento Valley during 1986. Sacramento, CA, USA.

Hansen, G. E. 1987. Review of the status of the giant garter snake (Thamnophis couchi gigas) and its supporting habitat during 1986-1987. Sacramento, CA, USA.

Hansen, G. E., and J. M. Brode. 1980. Status of the giant garter snake Thamnophis couchi gigas (Fitch). California Department of Fish and Game Inland Fisheries Endangered Species Program, Sacramento, CA, USA.

Hansen, R. W. 1980. Western aquatic garter snakes in central California: an ecological and evolutionary perspective. Thesis, California State University, Fresno, CA, USA.

Hayes, W. K., R. A. Escobar III, S. K. Fry, E. M. Fortune, J. A. Wasilewski, D. M. Tuttle, K. S. West, J. B. Iverson, S. D. Buckner, and R. L. Carter. 2016. Conservation of the endangered sandy cay rock iguanas (Cyclura rileyi cristata): invasive species control, population response, pirates, poaching, and translocation. Herpetological Conservation and Biology 11:106-120.

Henkanaththegedara, S. M., and C. A. Stockwell. 2014. Intraguild predation may facilitate coexistence of native and non-native fish. Journal of Applied Ecology 51:10571065.

ICF International. 2018. Biological effectiveness monitoring for the Natomas Basin Habitat Conservation Plan area: 2017 annual survey results. Sacramento, CA, USA.

Kiparsky, M., A. Milman, D. Owen, and A. T. Fisher. 2017. The importance of institutional design for distributed local-level governance of groundwater: the case of California's Sustainable Groundwater Management Act. Water (Switzerland) 9:1-17.

Linquist, B., R. Snyder, F. Anderson, L. Espino, G. Inglese, S. Marras, R. Moratiel, R. Mutters, P. Nicolosi, H. Rejmanek, A. Russo, T. Shapland, Z. Song, A. Swelam, G. Tindula, and J. Hill. 2015. Water balances and evapotranspiration in water- and 
dry-seeded rice systems. Irrigation Science 33:375-385.

Musoke, M. S., and A. L. Olmstead. 1982. The rise of the cotton industry in California: a comparative perspective. The Journal of Economic History 42:385-412.

Noonburg, E. G., and J. E. Byers. 2005. More harm than good: when invader vulnerability to predators enhances impact on native species. Ecology 86:2555-2560.

Reyes, G. A., B. J. Halstead, J. P. Rose, J. S. M. Ersan, A. C. Jordan, A. M. Essert, K. J. Fouts, A. M. Fulton, K. B. Gustafson, R. F. Wack, G. D. Wylie, and M. L. Casazza. 2017. Behavioral response of giant gartersnakes (Thamnophis gigas) to the relative availability of aquatic habitat on the landscape. U.S. Geological Survey Open-File Report 2017-1141.

Rose, J. P., J. S. M. Ersan, G. D. Wylie, M. L. Casazza, and B. J. Halstead. 2018a. Reproductive frequency and size-dependence of fecundity in the giant gartersnake (Thamnophis gigas). Herpetological Conservation and Biology 13:80-90.

Rose, J. P., J. S. M. Ersan, G. D. Wylie, M. L. Casazza, and B. J. Halstead. 2019. Demographic factors affecting population growth in giant gartersnakes. Journal of Wildlife Management 83:1540-1551.

Rose, J. P., B. J. Halstead, G. D. Wylie, and M. L. Casazza. 2018b. Spatial and temporal variability in growth of giant gartersnakes: plasticity, precipitation, and prey. Journal of Herpetology 52:40-49.

Rose, J. P., and B. D. Todd. 2014. Projecting invasion risk of non-native watersnakes (Nerodia fasciata and Nerodia sipedon) in the western United States. PLoS ONE 9:e100277.

Rose, J. P., G. D. Wylie, M. L. Casazza, and B. J. Halstead. 2018c. Integrating growth and capture-mark-recapture models reveals size-dependent survival in an elusive species. Ecosphere 9:e02384.

Rosenzweig, M. L. 2003. Reconciliation ecology and the future of species diversity. Oryx 37:194-205.

Rossman, D. A., N. B. Ford, and R. A. Seigel. 1996. The Garter Snakes: Evolution and Ecology. University of Oklahoma Press, Norman, OK, USA.

Royle, J. A., A. K. Fuller, and C. Sutherland. 2018. Unifying population and landscape ecology with spatial capture-recapture. Ecography 41:444-456.

Schellekens, T., and T. van Kooten. 2012. Coexistence of two stage-structured intraguild predators. Journal of Theoretical Biology 308:36-44.

Sleeter, B. M., T. S. Wilson, E. Sharygin, and J. T. Sherba. 2017. Future scenarios of land change based on empirical data and demographic trends. Earth's Future 5:10681083.

Sloan, J. 2004. Progress report for the San Joaquin Valley giant garter snake conservation project-2004. Los Banos, CA, USA.

de Sobrino, C. N., C. L. Feldheim, and T. W. Arnold. 2017. Distribution and derivation of dabbling duck harvests in the Pacific Flyway. California Fish and Game 103:118137.

Spurgeon, J. J., C. P. Paukert, B. D. Healy, C. A. Kelley, and D. P. Whiting. 2015. Can translocated native fishes retain their trophic niche when confronted with a resident invasive? Ecology of Freshwater Fish 24:456-466.

Swain, D. L., B. Langenbrunner, J. D. Neelin, and A. Hall. 2018. Increasing precipitation volatility in twenty-first-century California. Nature Climate Change 8:427-433.

Torbick, N., and W. Salas. 2014. Mapping agricultural wetlands in the Sacramento Valley, 
USA, with satellite remote sensing. Wetlands Ecology and Management 23:7994.

U.S. Fish and Wildlife Service (USFWS). 1993. Determination of threatened status for the giant garter snake. Federal Register 58:54053-54066.

U.S. Fish and Wildlife Service (USFWS). 2017. Recovery plan for the giant garter snake (Thamnophis gigas). Sacramento, CA, USA.

U.S. Fish and Wildlife Service (USFWS). 2020. Giant gartersnake (Thamnophis gigas) 5-year review: summary and evaluation. Sacramento, CA, USA.

Valcarcel, P. M. 2011. Giant gartersnake spatial ecology in agricultural and constructed wetlands. Thesis, Oregon State University, Corvallis, OR, USA.

Wood, D. A., B. J. Halstead, M. L. Casazza, E. C. Hansen, G. D. Wylie, and A. G. Vandergast. 2015. Defining population structure and genetic signatures of decline in the giant gartersnake (Thamnophis gigas): implications for conserving threatened species within highly altered landscapes. Conservation Genetics 16:1025-1039.

Wright, A. H., and A. A. Wright. 1957. Handbook of Snakes of the United States and Canada, Volume II. Comstock Publishing Associates, Ithaca, NY, USA.

Wylie, G. D., and M. Amarello. 2006. Surveys for the current distribution and abundance of giant garter snakes (Thamnophis gigas) in the southern San Joaquin Valley. Sacramento, CA, USA.

Wylie, G. D., M. L. Casazza, and N. M. Carpenter. 2003. Diet of bullfrogs in relation to predation on giant garter snakes at Colusa National Wildlife Refuge. California Fish and Game 89:139-145.

Wylie, G. D., M. L. Casazza, C. J. Gregory, and B. J. Halstead. 2010. Abundance and sexual size dimorphism of the giant gartersnake (Thamnophis gigas) in the Sacramento Valley of California. Journal of Herpetology 44:94-103.

Submitted 30 September 2020

Accepted 5 November 2020

Associate Editor was J. Olson 